\title{
A randomized controlled trial of Tai chi for balance, sleep quality and cognitive performance in elderly Vietnamese
}

\section{Manh Hung Nguyen \\ Andreas Kruse}

Institute of Gerontology, Heidelberg University, Heidelberg, Germany
Correspondence: Manh Hung Nguyen Institute of Gerontology,

Bergheimerstrasse 20,

69115 Heidelberg, Germany

Tel +496221548170

Fax +496221 545961

Email hung.nguyen@gero.uni-heidelberg.de
This article was published in the following Dove Press journal:

Clinical Interventions in Aging

21 June 2012

Number of times this article has been viewed

Objective: To evaluate the effects of Tai chi exercise on balance, sleep quality, and cognitive performance in community-dwelling elderly in Vinh city, Vietnam.

Design: A randomized controlled trial.

Participants: One hundred two subjects were recruited.

Intervention: Subjects were divided randomly into two groups. The Tai chi group was assigned 6 months' Tai chi training. The control group was instructed to maintain their routine daily activities.

Outcome measures: The Falls Efficacy Scale (FES), Pittsburgh Sleep Quality Index (PSQI), and Trail Making Test (TMT) were used as primary outcome measures

Results: Participants in the Tai chi group reported significant improvement in TMT (part A) $(\mathrm{F}[1,71]=78.37, P<0.001)$ and in TMT (part B), $(\mathrm{F}[1,71]=175.00, P<0.001)$ in comparison with the control group. Tai chi participants also reported better scores in FES (F $[1,71]=96.90$, $P<0.001)$ and in PSQI $(\mathrm{F}[1,71]=43.69, P=0.001)$ than the control group.

Conclusion: Tai chi is beneficial to improve balance, sleep quality, and cognitive performance of the elderly.

Keywords: Tai chi, sleep, balance

\section{Introduction}

Muscle weakness, impaired gait, and diminished balance are the most significant risk factors for falling. ${ }^{1}$ It has been documented that physical activities are based on balance ability; when the perturbation increases and leads to an unstable balance state of the trunk, a fall is more likely. Balance is the ability to maintain the body's position over its base of support, whether that base is stationary or moving. ${ }^{2}$ Previous studies, on the other hand, have shown that poor sleep in older people is related to impaired health status, low levels in physical activities, poor physical functioning, and an increase in chronic diseases. ${ }^{3,4}$ Moreover, a review of Angevaren et $\mathrm{al}^{5}$ concluded that aerobic physical activities that improve cardiorespiratory fitness are beneficial for cognitive function in healthy older adults, with effects observed for motor function, cognitive speed, and auditory and visual attention. However, the majority of comparisons yielded no significant results.

Tai chi consists of series of gentle physical activities with element and meditation, body awareness, imagery, and attention to breathing. ${ }^{6}$ Furthermore, Tai chi is a low-intensity exercise that provides aerobic benefit ${ }^{7}$ and is effective for improving fitness. ${ }^{8}$ Tai chi also appears to have physiological and psychological benefits, and to be safe and effective in promoting balance control, flexibility, and cardiovascular fitness. ${ }^{9}$ 
To our knowledge, there have been few studies on effects of Tai chi on sleep quality, cognitive performance, and balance of community-dwelling older people. Thus, it would be worthwhile to carry out a study on the aforementioned issues.

\section{Materials and methodology} Participants

Ninety-six community-dwelling participants were recruited at age 60-79 years $(68.9 \pm 5.1)$ from Vinh city to undertake a Tai chi program. Six subjects $(6.2 \%)$ dropped out within 3 months (first phase). Seventeen subjects (17.7\%) dropped out during the next 3 months. The 6-month Tai chi training included pre- and post-training and follow-up (follow-up used only for Tai chi group). Inclusion criteria of both groups included the subjects being able to finish the Mini Mental State Examination (MMSE) with a score greater than 25 and having no experience in Tai chi. Exclusion criteria included subjects with serious diseases, such as symptomatic coronary insufficiency, angina, arrhythmia, orthostatic hypotension, and dementia.

\section{Intervention}

In a randomized, controlled trial, 102 subjects were recruited. Six subjects did not meet the exclusion criteria (Mini Mental State Examination score $\geq 25$ ). Subjects were divided randomly into two groups - Tai chi group and control group. The subjects were expected to consent and volunteer. Participants in the Tai chi group $(n=48$, mean age $=69.2$ years, standard deviation $=5.3$ ) were assigned 6 months' Tai chi training. Participants in the control group $(n=48$, mean age $=68.7$, standard deviation $=4.9$ ) were instructed to maintain their routine daily activities and not to begin any new exercise programs. Statistical analysis was based on previous findings, ${ }^{10,11}$ using the standardized mean difference of the group means, alpha level $=0.05$, desired statistical power $=0.8$, and effect size set at medium (0.5). Experienced Tai chi instructors were selected by investigators to teach classes. The version of Tai chi followed was the 24-form style, which incorporates elements of balance, postural alignment, and concentration.

Participants in the Tai chi group attended a 60-minute Tai chi practice session twice a week for 6 months. The session consisted of a 15-minute warm-up and a 15-minute cool-down period. Participants in the control group were instructed to maintain their routine daily activities.

\section{Main outcome measures}

The Falls Efficacy Scale (FES), an instrument to measure fear of falling, was designed to assess the degree of perceived efficacy at avoiding falls during each of ten relatively nonhazardous activities of daily living (as previously described by Tinetti et $\mathrm{al}^{12}$ ).

The Pittsburgh Sleep Quality Index (PSQI) is an effective instrument used to measure the quality and patterns of sleep of older adults (as previously described in Buysse et $\mathrm{al}^{13}$ ).

The Trail Making Test (TMT) is primarily a test of motor speed and visual attention. In TMT part A, the subject's task is to quickly draw the lines on a page connecting 25 consecutive numbers. In part B, the subjects must draw the lines alternating between number and letter. Both parts of the TMT consist of 25 circles distributed over a sheet of paper (as described in Corrigan and Hinkeldey, ${ }^{14}$ Gaudino et $\mathrm{al}^{15}$ and $\operatorname{Reitan}^{16}$ ).

\section{Statistical analyses}

Analysis of variance was used to analyze the differencedependent variables of tests. General linear repeated measures were used to identify interaction between types of intervention and test time and within-subject main effect. A value of $P<0.05$ was considered to be statistically significant.

\section{Results}

Descriptive characteristics of the samples in both the Tai chi and control groups are shown in Table 1: the age range (year), average age value (year), body mass index range $\left(\mathrm{kg} / \mathrm{m}^{2}\right)$, waist-hip ratio range $(\mathrm{cm})$, marital status (number, percentage), and years of education.

\section{Comparison of sleep quality, balance, and cognitive performance between Tai chi and control groups at baseline} Results (Table 2) show that there were no significant differences in independent variables between the Tai chi and control groups at baseline.

\section{Comparison of sleep quality, balance, and cognitive performance between Tai chi and control groups at end test}

Results (Table 3 ) show that there were significant differences in independent variables between the Tai chi and control groups at end test. Results from PSQI indicated sleep quality between the two groups, with $\mathrm{F}(1,71)=43.69, P<0.001$; cognitive performance can be observed from TMT part A, with $\mathrm{F}(1,71)=78.37, P<0.001$; TMT part $\mathrm{B}$, with $\mathrm{F}(1,71)=175.90, P<0.001$; and balance ability in FES, with $\mathrm{F}(1,71)=96.90, P<0.001$. 
Table I Characteristics of the study sample

\begin{tabular}{|c|c|c|c|c|}
\hline Characteristics & & Number (percentage) & & \\
\hline \multicolumn{5}{|c|}{ Marital status (for both groups) } \\
\hline Living with other & & $24(25)$ & & \\
\hline Married & & $53(55.2)$ & & \\
\hline Widowed & & $13(13.5)$ & & \\
\hline Single & & I (I.0) & & \\
\hline Not say & & $5(5.2)$ & & \\
\hline \multicolumn{5}{|l|}{ Education (yrs) } \\
\hline $5-9$ & & $24(25)$ & & \\
\hline $10-12$ & & $45(49.6)$ & & \\
\hline \multirow[t]{2}{*}{$>12$} & & $27(28.1)$ & & \\
\hline & Tai chi group & & Control group & \\
\hline Number of participants & 48 & & 48 & \\
\hline Male & 24 & & 24 & \\
\hline \multirow[t]{2}{*}{ Female } & 24 & & 24 & \\
\hline & Mean & SD & Mean & SD \\
\hline Age & 69.23 & 5.30 & 68.73 & 4.95 \\
\hline BMI $\left(\mathrm{kg} / \mathrm{m}^{2}\right)$ & 24.14 & 1.38 & 24.42 & 0.71 \\
\hline WHR (cm) & 0.94 & 0.06 & 0.95 & 0.03 \\
\hline
\end{tabular}

Abbreviations: BMI, Body Mass Index; WHR, Waist Hip Ratio.

Table 2 One-way ANOVA between Tai chi and control groups at baseline

\begin{tabular}{lcccc}
\hline Dependent variables & Mean \pm SD & F $(\mathbf{I}, \mathbf{9 4})$ & Significance* \\
\cline { 2 - 4 } & Tai chi $(\mathbf{n}=\mathbf{4 8})$ & Control $(\mathbf{n}=\mathbf{4 8})$ & & 0.162 \\
\hline PSQI & $9.38 \pm 4.99$ & $8.06 \pm 4.09$ & 1.985 & 0.066 \\
FES & $54.71 \pm 8.37$ & $51.56 \pm 8.21$ & 3.453 & \\
TMT & & & & 0.081 \\
Part A & $45.40 \pm 6.78$ & $45.04 \pm 5.33$ & 2.152 & 0.777 \\
Part B & $117.06 \pm 6.74$ & $119.25 \pm 7.82$ & & 0.146 \\
\hline
\end{tabular}

Note: *Determined by ANOVA.

Abbreviations: PSQI, Pittsburgh Sleep Quality Index; FES, the Falls Efficacy Scale; TMT, Trail Making Test.

Table 3 One-way ANOVA between Tai chi and control groups at end test

\begin{tabular}{lcccc}
\hline Dependent variables & Mean \pm SD & F $(\mathbf{I}, \mathbf{7 I})$ & Significance* \\
\cline { 2 - 4 } & Tai chi $(\mathbf{n}=\mathbf{3 9})$ & Control $(\mathbf{n}=\mathbf{3 4})$ & & 0.000 \\
\hline PSQI & $3.59 \pm 1.56$ & $7.97 \pm 3.78$ & 43.69 & 0.000 \\
FES & $35.20 \pm 5.89$ & $51.35 \pm 8.06$ & 96.90 & \\
TMT & & & & \\
Part A & $35.05 \pm 4.31$ & $44.24 \pm 4.54$ & 78.37 & 0.000 \\
Part B & $102.05 \pm 5.01$ & $118.32 \pm 6.36$ & 175.90 & 0.000 \\
\hline
\end{tabular}

Note: *Determined by ANOVA.

Abbreviations: PSQI, Pittsburgh Sleep Quality Index; FES, the Falls Efficacy Scale; TMT, Trail Making Test.

Table 4 General linear model-repeated measures of variables

\begin{tabular}{|c|c|c|c|c|c|}
\hline Measurement & MS & df & $\mathbf{F}$ & Significance & $(\eta)$ \\
\hline \multirow[t]{2}{*}{ PSQI (total) } & 246.27 & I.I45, 142 & $49.50^{\S}$ & 0.000 & 0.411 \\
\hline & 129.22 & I.I45, 142 & $25.97 \S \S$ & 0.000 & 0.268 \\
\hline \multirow[t]{2}{*}{ FES } & 2189.15 & $1.659,142$ & $310.63^{\S}$ & 0.000 & 0.814 \\
\hline & 2329.40 & $1.659,142$ & $329.18^{\S \S}$ & 0.000 & 0.823 \\
\hline \multicolumn{6}{|l|}{ TMT } \\
\hline \multirow[t]{2}{*}{ Part A } & 764.37 & I.449, I 42 & $208.87^{\S}$ & 0.000 & 0.746 \\
\hline & 613.68 & $1.449,142$ & $171.74^{\S \S}$ & 0.000 & 0.708 \\
\hline \multirow[t]{2}{*}{ Part B } & 1686.37 & I.357, 142 & $435.65^{\S}$ & 0.000 & 0.860 \\
\hline & 1601.50 & I.357, 142 & $413.73^{\S \S}$ & 0.000 & 0.854 \\
\hline
\end{tabular}

Notes: ${ }^{\circledR}$ Test time; ${ }^{\S}$ Test time*group; $\eta=$ Eta squared.

Abbreviations: PSQI, Pittsburgh Sleep Quality Index; FES, the Falls Efficacy Scale; TMT, Trail Making Test. 


\section{Comparison of results from three periods of tests between Tai chi and control groups}

There were significant interactions in sleep quality, balance, and cognitive performance between the two groups and test times. This can be observed from the results shown in Table 4 $(P<0.001)$, and also from the four figures that illustrate the estimated means of PSQI (Figure 1), FES (Figure 2), TMT part A (Figure 3), and TMT part B (Figure 4) between the Tai chi and control groups over the test times. The Tai chi group showed better results than the control group for all variables.

\section{Discussion}

In this study, we examined the effects of 24-form Tai chi exercise during 6 months on sleep quality, balance, and cognitive performance of older community-dwelling people. On the basis of this study, it may be concluded that 24-week Tai chi training has a positive effect on sleep quality, balance, and cognitive performance of the community-dwelling elderly in Vietnam. The main findings of this study were that older adults benefited from Tai chi exercise for sleep quality (better scores in PSQI), whereas no improvement was observed for the control group. Results of balance tests and cognitive performance tests also strongly proved that Tai chi could improve the balance ability and cognitive executive function in comparison with subjects' counterparts in the control group.

It has been documented in previous studies that Tai chi could have better scores in the sit-and-reach test, total body rotation, ${ }^{17}$ and reduction in falls, ${ }^{18}$ which shows that a 12-week Tai chi exercise program can safely improve physical strength and blood pressure and reduce fall-prone older adults in residential care facilities. ${ }^{19,20}$ The results of our study are consistent with studies that have stated that Tai chi can improve the balance ability of older people $e^{21-23}$ and sleep quality, ${ }^{24}$ and we conclude that through a 6-month Tai chi program, participants with moderate sleep complaints can be improved in self-rated sleep quality. A previous finding ${ }^{25}$ also suggested that after a 10 -week tai chi program in older adults using a pre- to post-test design, cognitive executive function was improved. Tai chi is a traditional Chinese aerobic exercise. Its benefits are improvement in balance, flexibility, muscle strength, neuromuscular reaction, and endurance in elderly individuals. ${ }^{26-28}$ Tai chi has also been suggested as a useful nonpharmacological approach to sleep problems in older adults, ${ }^{24}$ and this is a low-technology exercise that can be easily carried out in a variety of communities.

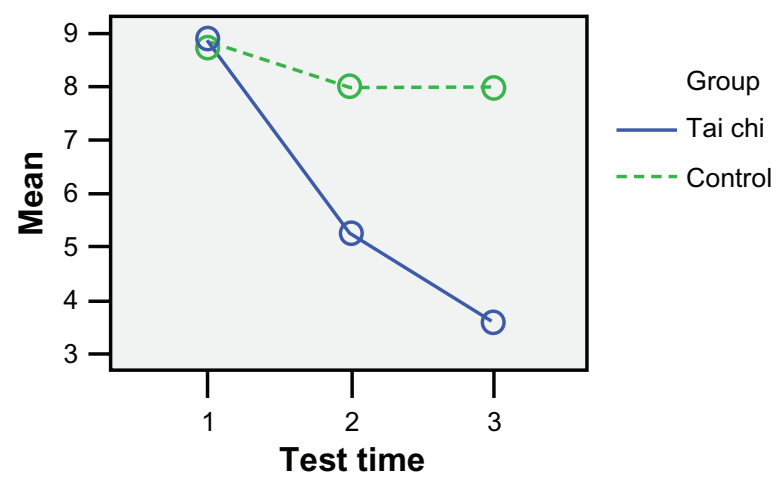

Figure I Mean of PSQI at three test times.

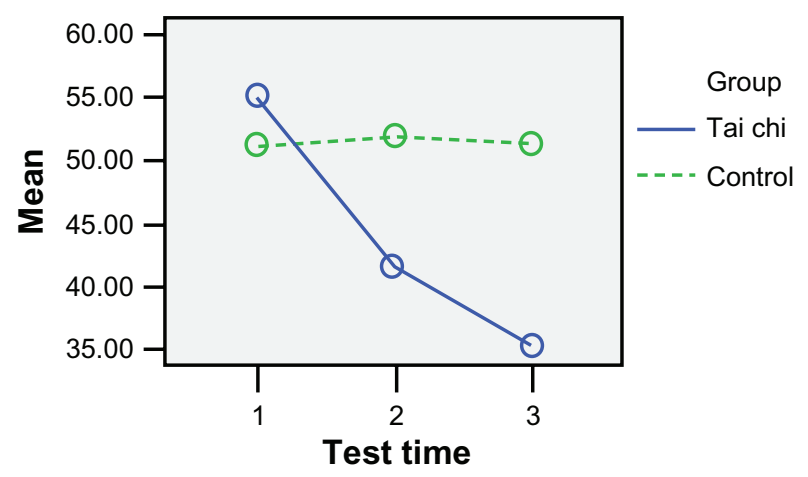

Figure 2 Mean of FES at three test times.

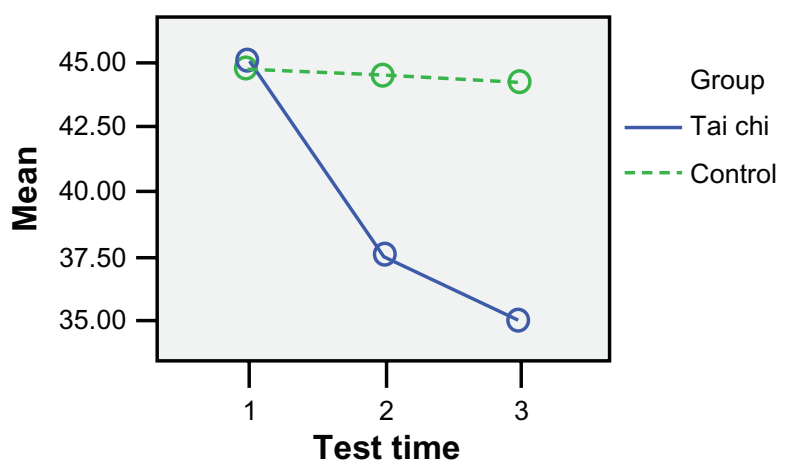

Figure 3 Mean of TMT of part A at three test times.

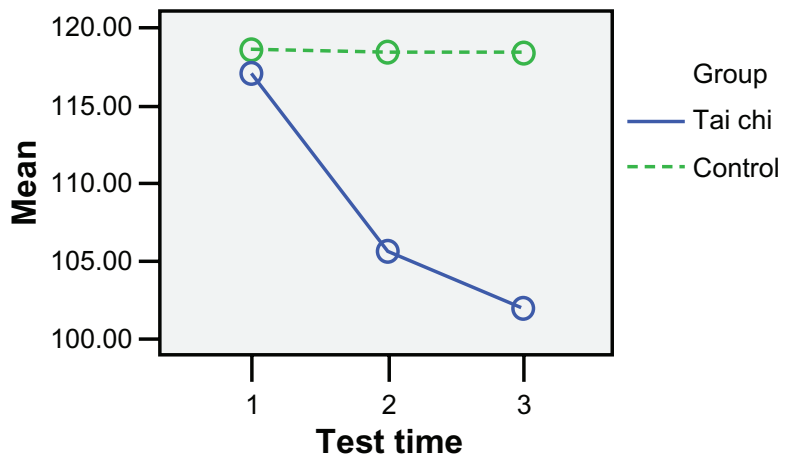

Figure 4 Mean of TMT of part B at three test times. 
Furthermore, Tai chi is a low-cost exercise, ${ }^{11}$ and it can be practiced indoor or outdoor.

Over the 6-month Tai chi program, we had an 18.75\% drop-out rate in the Tai chi group. This is evidence that a relatively high proportion of participants were likely to engage in Tai chi training. The attrition in participation was due mainly to traveling or leaving the city rather than dissatisfaction with the training program.

\section{Conclusion}

In this 24-week randomized controlled trial study, Tai chi is beneficial to improve sleep quality, balance, and cognitive performance of community-dwelling older people.

\section{Further study}

This study focused on a healthy group of older communitydwelling adults living in Vietnam. Other populations should be observed, the frail, for instance. The effects of Tai chi for people with osteoporosis, Parkinson's, arthritis and other chronic diseases have been documented elsewhere. However, empirical and controlled trial studies should be carried out widely. In future, Tai chi programs should be compared to other sport or recreational activity programs to see less biased effects.

\section{Acknowledgments}

This work was supported by grant no 3612/QD-BGDDT from the Vietnam International Education Development; travel grant from Graduiertenakademie Universität Heidelberg/ Heidelberg University Graduate Academy, Institute of Gerontology, Heidelberg University, Germany; and Tai chi club in Vinh city, Vietnam.

\section{Disclosure}

There are no conflicts of interest in this work. The study sponsors played no role in the study design, collection and analysis of data, writing of the manuscript, or decision to submit the manuscript for publication.

\section{References}

1. Daley MJ, Spinks WL. Exercise, mobility and aging. Sports Med. 2000; 29(1):1-12.

2. Spirduso WW. Physical Dimensions of Aging. Champaign: Human Kinetics; 1995.

3. Gooneratne N, Weaver T, Cater J, et al. Functional outcomes of excessive daytime sleepiness in older adults. J Am Geriatr Soc. 2003;51(5): 462-469.

4. Newman A, Spiekerman C, Enright P, et al. Daytime sleepiness predicts mortality and cardiovascular disease in older adults. J Am Geriatr Soc. 2000;48(2):115-123.
5. Angevaren M, Aufdemkampe G, Verhaar H, Aleman A, Vanhees L. Physical activity and enhanced fitness to improve cognitive function in older people without known cognitive impairment. Cochrane Database Syst Rev. 2008;2:CD005381.

6. Yeh GY. Commentary on the Cochrane review of Tai Chi for rheumatoid arthritis. Explore (NY). 2008;4(4):275-277.

7. Li FZ, Harmer P, McAuley E, Fisher KJ, Duncan TE, Duncan SC. Tai Chi, self-efficacy, and physical function in the elderly. Prev Sci. 2001; 2(4):229-239.

8. Lan C, Lai JS, Chen SY, Wong MK. 12-month Tai Chi training in the elderly: its effect on health fitness. Med Sci Sports Exerc. 1998;30(3): 345-351.

9. Wang C, Collet JP, Lau J. The effect of Tai Chi on health outcomes in patients with chronic conditions: a systematic review. Arch Intern Med. 2004;164(5):493-501.

10. Li FZ, Duncan TE, McAuley E, Harmer P. Delineating the impact of Tai Chi training on physical function among elderly: modeling the moderating effects of unobserved class trajectories. Am J Prev Med. 2002;23:92-97.

11. Li FZ, Harmer P, McAuley E, et al. An evaluation of the effects of Tai Chi exercise on physical function among older persons: a randomized contolled trial. Ann Behav Med. 2001;23(2):139-146.

12. Tinetti ME, Richman D, Powell L. Falls Efficacy as a measure of fear of falling. J Gerontol. 1990;45(6):239-243.

13. Buysse DJ, Reynolds CF, Monk TH, Berman SR, Kupfer DJ. The Pittsburgh Sleep Quality Index (PSQI): a new instrument for psychiatric research and practice. Psychiatry Res. 1989;28:193-213.

14. Corrigan JD, Hinkeldey MS. Relationships between parts A and B of the Trail Making Test. J Clin Psychol. 1987;34(4):402-409.

15. Gaudino EA, Geisler MW, Squires NK. Construct validity in the Trail Making Test: what makes part B harder? J Clin Exp Neuropsychol. 1995;17(4):529-535.

16. Reitan RM. Validity of the trail making test as an indicator of organic brain damage. Percept Mot Skills. 1958;8:271-276.

17. Hong Y, Li JX, Robinson PD. Balance control, flexibility, and cardiorespiratory fitness among older Tai Chi practitioners. Br J Sports Med. 2000;34(1):29-34.

18. Choi JH, Moon JS, Song R. Effects of Sun-style Tai Chi exercise on physical fitness and fall prevention in fall-prone older adults. $J A d v$ Nurs. 2005;51(2):150-157.

19. Ko GT, Tsang PC, Chan HC. A 10-week Tai-Chi program improved the blood pressure, lipid profile and SF-36 scores in Hong Kong Chinese women. Med Sci Monit. 2006;12(5):CR196-CR199.

20. Tsai JC, Wang WH, Chan P, et al. The beneficial effects of Tai Chi Chuan on blood pressure and lipid profile and anxiety status in a randomized controlled trial. J Altern Complem Med. 2003;9(5):747-754.

21. Hain TC, Fuller L, Weil, Kotsias J. The effects of Tai chi on balance. Arch Otolaryngo. 1999;125(11):1191-1195.

22. Hackney ME, Earhart GM. Tai Chi improves balance and mobility in people with Parkinson disease. Gait Posture. 2008;28(3):456-460.

23. Fong SM, Ng GY. The effects on sensorimotor performance and balance with Tai Chi training. Arch Phys Med Rehabil. 2006;87(1):82-87.

24. Li FZ, Fisher KJ, Harmer P, Irbe D, Tearse RG, Weimer C. Tai chi and self-rated quality of sleep and daytime sleepiness in older adults: a randomized controlled trial. J Am Geriatr Soc. 2004;52(6):892-900.

25. Matthews MM, Williams HG. Can Tai chi enhance cognitive vitality? A preliminary study of cognitive executive control in older adults after A Tai chi intervention. J S C Med Assoc. 2008;104(8):255-257.

26. Lan C, Lai JS, Chen SY, Wong MK. Tai Chi Chuan to improve muscular strength and endurance in elderly individuals: a pilot study. Arch Phys Med Rehabil. 2000;81(5):604-607.

27. Taylor AH, Cable NT, Faulkner G, Hillsdon M, Narici M, Van Der Bij AK. Physical activity and older adults: a review of health benefits and the effectiveness of interventions. J Sports Sci. 2004;22(8):703-725.

28. Xu DQ, Li JX, Hong YL. Effect of regular Tai Chi and jogging exercise on neuromuscular reaction in older people. Age Ageing. 2005;34(5): $439-444$. 
Clinical Interventions in Aging

Dovepress

\section{Publish your work in this journal}

Clinical Interventions in Aging is an international, peer-reviewed journal focusing on evidence-based reports on the value or lack thereof of treatments intended to prevent or delay the onset of maladaptive correlates of aging in human beings. This journal is indexed on PubMed Central, MedLine, the American Chemical Society's 'Chemical Abstracts Ser-

vice' (CAS), Scopus and the Elsevier Bibliographic databases. The manuscript management system is completely online and includes a very quick and fair peer-review system, which is all easy to use. Visit $\mathrm{http}: / / \mathrm{www}$.dovepress.com/testimonials.php to read real quotes from published authors.

Submit your manuscript here: http://www.dovepress.com/clinical-interventions-in-aging-journal 